\title{
The European lightning location system EUCLID - Part 1: Performance analysis and validation
}

\author{
Wolfgang Schulz ${ }^{1}$, Gerhard Diendorfer ${ }^{1}$, Stéphane Pedeboy ${ }^{2}$, and Dieter Roel Poelman ${ }^{3}$ \\ ${ }^{1}$ OVE-ALDIS, Vienna, Austria \\ ${ }^{2}$ Meteorage, Pau, France \\ ${ }^{3}$ Royal Meteorological Institute of Belgium, Brussels, Belgium
}

Correspondence to: Wolfgang Schulz (w.schulz@ove.at)

Received: 27 July 2015 - Published in Nat. Hazards Earth Syst. Sci. Discuss.: 4 September 2015

Revised: 8 February 2016 - Accepted: 23 February 2016 - Published: 2 March 2016

\begin{abstract}
In this paper we present a performance analysis of the European lightning location system EUCLID for cloud-to ground flashes/strokes in terms of location accuracy (LA), detection efficiency (DE) and peak current estimation. The performance analysis is based on ground truth data from direct lightning current measurements at the Gaisberg Tower (GBT) and data from E-field and video recordings. The E-field and video recordings were collected in three different regions in Europe, namely in Austria, Belgium and France. The analysis shows a significant improvement of the LA of the EUCLID network over the past 7 years. Currently, the median LA is in the range of $100 \mathrm{~m}$ in the center of the network and better than $500 \mathrm{~m}$ within the majority of the network. The observed DE in Austria and Belgium is similar, yet a slightly lower DE is determined in a particular region in France, due to malfunctioning of a relevant lightning location sensor during the time of observation. The overall accuracy of the lightning location system (LLS) peak current estimation for subsequent strokes is reasonable keeping in mind that the LLS-estimated peak currents are determined from the radiated electromagnetic fields, assuming a constant return stroke speed.

The results presented in this paper can be used to estimate the performance of the EUCLID network related to cloud-toground flashes/strokes for regions with similar sensor baselines and sensor technology.
\end{abstract}

\section{Introduction}

Lightning location data have been used by power utilities, meteorological services and other lightning sensitive operations for more than 20 years. In the case of power utilities the data are important to support the network operator in order to increase the power system availability and to provide warning information for maintenance crews in case of approaching thunderstorms. For all applications of lightning data, it is important to know the performance of the employed lightning location system (LLS) related to cloud-to-ground (CG) flashes/strokes in terms of location accuracy (LA) and detection efficiency (DE). Often it is tried to determine the performance of an LLS by network cross comparison with data from different LLS covering the same area (Drüe et al., 2007; Poelman et al., 2013a) but such comparisons typically do not provide any clear results as long as none of the two networks is of high and validated performance. Ideally one of the networks should be a kind of reference network for a certain performance parameter. Therefore, a direct comparison of LLS data with ground truth data is the best way to validate the performance of an LLS.

Different approaches to collect ground truth data of lightning discharges related to CG flashes/strokes are used:
a. lightning to instrumented towers;
b. rocket-triggered lightning;
c. video and E-field records of lightning discharges.

Each of these methods has different advantages and limitations (for more details see Nag et al., 2015). In order to 
evaluate the performance of the EUCLID (European Cooperation for Lightning Detection) LLS in terms of LA, DE and the accuracy of the peak current estimate, we are using approaches (A) and (C) in this paper for the collection of ground truth data by using data from the direct lightning current measurement at the Gaisberg Tower (GBT) (Diendorfer et al., 2009a), and video and E-field records of lightning data collected in three different regions (Austria, Belgium and France) in Europe (Poelman et al., 2013b), respectively. Those measurements should be representative for all regions in Europe covered by the EUCLID network with similar sensor baselines. We do not present any data on polarity errors because by comparing LLS data with independent Efield measurement data we have never observed such errors since we started the measurements.

In the past, several analyses were made to estimate the EUCLID performance in the early stage of the network (before 2005, the beginning of the data analysis in this paper), e.g., in Slovenia where LLS data were compared to data from GPS synchronized flash counters installed on mobile phone towers (Djurica and Kosmač, 2006; Djurica et al., 2009), in France where video surveys were used to determine the actual network performance of the French lightning location system (Berger and Pedeboy, 2003) and in Austria where a continuous E-Field measurement system was developed to evaluate the network performance (Schulz and Diendorfer, 2006), together with measurements at the GBT (Diendorfer et al., 2002). Further data from a VHF mapping system (Lightning Mapping Array) were used during the HyMeX experiment (Ducrocy et al., 2013; Defer et al., 2015) in the south of France to validate the EUCLID DE of intra-cloud discharges (Schulz et al., 2014b; Pédeboy et al., 2014).

The above mentioned network evaluation projects were performed during different time periods in different regions of the EUCLID network. With this paper we want to show the present status of the network performance and provide a base for the companion paper by Poelman and coworkers (Poelman et al., 2016).

\section{EUCLID network}

In 2001 several countries (Austria, France, Germany, Italy, Norway and Slovenia) started a cooperation named EUCLID. The goal of this cooperation is to provide to the end users "European-wide" lightning data of high and nearly homogeneous quality. Since that time also Spain, Portugal, Finland, Sweden and Belgium joined EUCLID. The EUCLID cooperation is special in the sense that it is the merge of independent national networks, and the individual partners are highly motivated to run their local networks with state-ofthe-art lightning detection sensors. All the partners employ dedicated technicians to supervise and maintain the network and to react in short time in case of sensor or communication problems. As of December 2014 the EUCLID net-

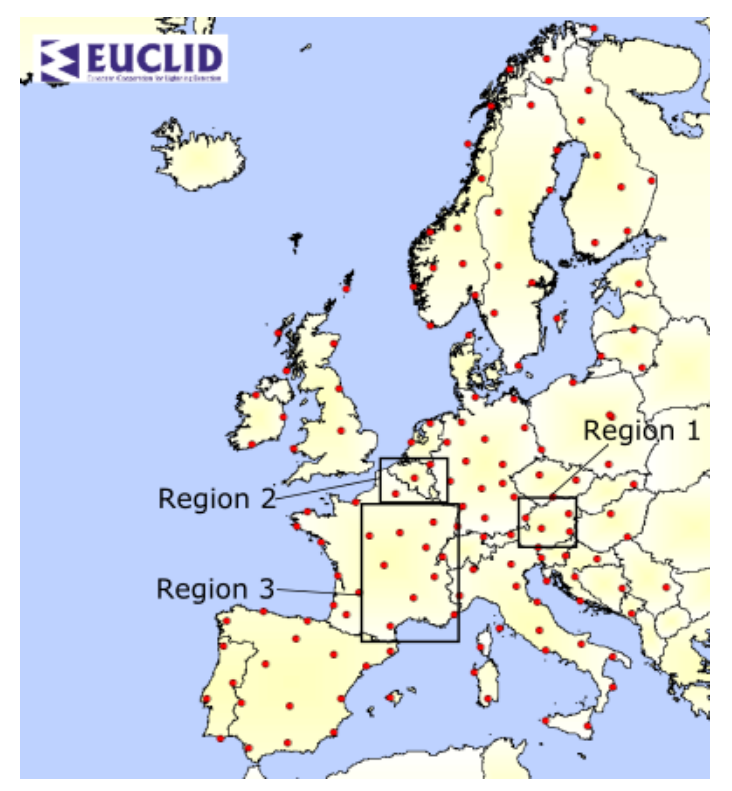

Figure 1. EUCLID network configuration for 2014. Sensor locations are shown as red dots.

work employs 149 sensors: 7 LPATS, 10 IMPACT, 31 IMPACT ES/ESP and 101 LS700x sensors, when listed in order from the oldest to the newest sensor version. All different sensor types, manufactured by Vaisala Inc., are operating in the same frequency range with individually calibrated sensor gains and sensitivities in order to account for any local sensor site conditions. Figure 1 shows the EUCLID network configuration as of 2014. In this figure also three areas labeled Region 1, Region 2 and Region 3, respectively, are indicated. In these three areas video and E-field records of lightning discharges were collected.

In addition to the processing carried out by each national LLS, data from all 149 sensors are processed in real-time using a central processor in Austria at ALDIS (Austrian Lightning Detection and Information System), which also provides daily performance analyses reports for each of the sensors. This assures that the resulting lightning data are as consistent as possible throughout Europe. In fact, the EUCLID data are frequently of higher quality than the data produced by individual national networks, being sub-networks of EUCLID. This is due to the implicit higher redundancy in EUCLID as a result of participation of additional sensors in the lightning location, which are located outside the national borders in a neighboring country. We note that there is a full backup EUCLID processing center in Germany with independent and direct data connections to all sensors. Further, the transnational EUCLID cooperation also acts as a platform for knowledge exchange related to lightning location technology and LLS data applications. Since the beginning of the cooperation, the performance of the EUCLID network has been steadily improved. Improvements are the result of employing more advanced location algorithms, of installing 
state of the art sensor technology, and relocating sensor positions in case of poorly performing sensor sites (e.g., local electromagnetic noise). Over the next 1-2 years, at least 10 of the remaining older type sensors are expected to be upgraded to the newest sensor type (LS700x).

Prior to 2005 the EUCLID network consisted of IMPACT and LPATS sensors only. More information about the setup of the original network in 2002 can be found in Schulz and Diendorfer (2002) and Diendorfer (2002). The following important changes and upgrades in the EUCLID network were made during the last 10 years.

- Start of the sensor upgrade to LS700X technology (2006) - The ALDIS network was the first network in Europe which was upgraded to the LS700x sensor technology in the beginning of 2006. At this time, not all the new features, described below, of the LS700x technology were used. Therefore the LS700x sensor was basically performing like an IMPACT sensor. Successively, more and more sensors were upgraded by other EUCLID members to the newest technology.

- New location algorithm (July 2008) - At this time an updated location algorithm was installed at the EUCLID central processor. This updated location algorithm does a more sophisticated job of grouping received sensor data to a given stroke and also performs iterations after rejection of originally considered sensor messages because their time or angle measurements did not fit with the estimated stroke location.

- "Sensor-based" onset time calculation (July 2011) Prior to 2011, the so-called onset time of the lightningradiated field arriving at the sensor site was estimated at the central processor (Honma et al., 1998). The onset time is the time information that is minimally altered by field propagation effects over different distances, and it is the time used for the location calculation based on the arrival time differences. Therefore, it is important to determine the onset time as precisely as possible. In 2011 a new feature at the LS700x sensor was put into operation, the so-called sensor-based onset time calculation (Honma et al., 2011). In this case, the onset time is derived as a linear extrapolation from the rising edge of the return stroke wave-front. This type of onset time calculation is significantly more accurate than the previously used estimation at the central processor.

- Propagation correction (December 2012) - In the complex terrain of the Alps, the correction of timing errors is very important. Those timing errors are the result of a combination of propagation effects due to finite ground conductivity and of an elongation of the propagation path (Honma et al., 2011). As the alpine region represents a large part of the area covered by the EUCLID network, those timing errors are important. In order to correct the timing errors for each sensor,

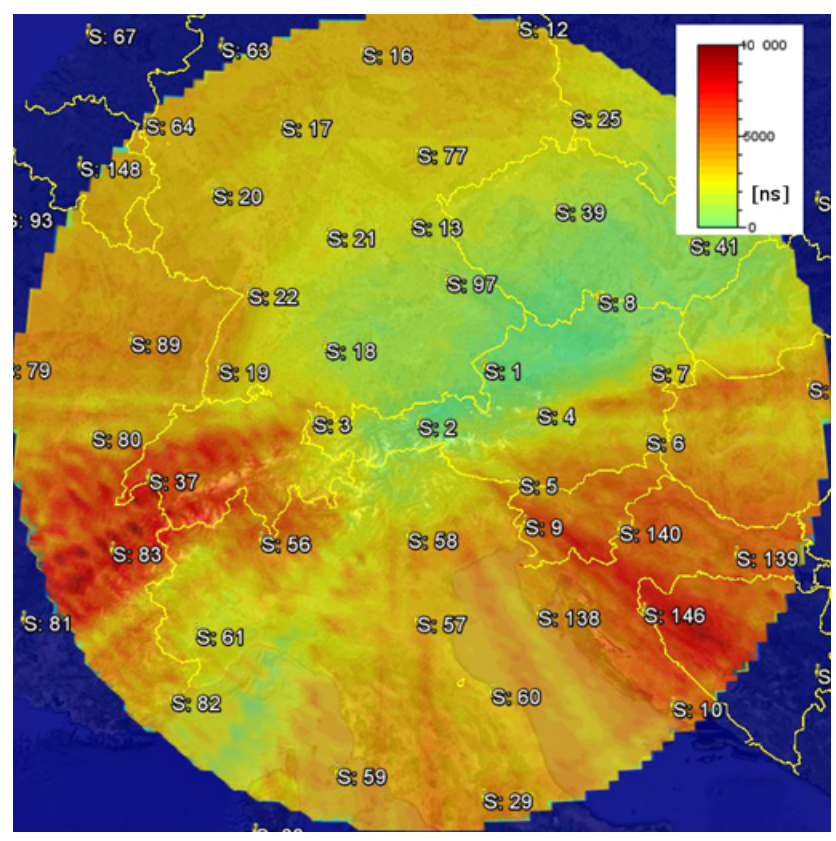

Figure 2. Example of a propagation correction determined and implemented for Austrian sensor \#2 (Schwaz). The sensor is located in the center of the circular area.

the distance- and angle-dependent time-correction values have been extracted from the historical sensor data and implemented as corrections in the central analyzer. As an example for the time error correction in the Alps, the angle- and distance-dependent time corrections of sensor \#2 (Schwaz) are shown in Fig. 2. This sensor \#2 is located in Austria in a mountain valley that stretches from west to east and is surrounded by high mountains (up to $3000 \mathrm{~m}$ a.s.l.). The highest mountains are in the south of the sensor site. Compared to sensors located in a more or less flat region this sensor site shows a very complex structure for timing correction. It shows large time errors in the west and in the south-east of the sensor location. All the regions in blue are outside the operational range $(600 \mathrm{~km})$ of this sensor and therefore not corrected for timing errors.

\section{Instrumentation}

\subsection{Gaisberg Tower (GBT)}

Since 1998, direct lightning strikes to a radio tower have been measured on the Gaisberg, a mountain next to the city of Salzburg in Austria (Diendorfer et al., 2009b). This $100 \mathrm{~m}$ high tower is located on the top of the Gaisberg (1287 m a.s.l.). Lightning flashes to the tower occur in summer as well as during winter time. The overall current waveforms are measured at the base of the air terminal installed on the top of the tower with a current-viewing shunt resis- 
tor of $0.25 \Omega \mathrm{m}$ having a bandwidth of $0 \mathrm{~Hz}$ to $3.2 \mathrm{MHz}$. A fiber optic link is used for transmission of the shunt output signal to a digital recorder installed in the building next to the tower. The signals were recorded by an 8 bit digitizing board installed in a personal computer. The trigger threshold of the recording system was set to $200 \mathrm{~A}$ with a pre-trigger recording time of $15 \mathrm{~ms}$. The lower measurement limit given by the 8 bit digitizer resolution was about $15 \mathrm{~A}$. For noise reduction the current records acquired at the GBT are filtered using a digital low pass filter (Butterworth, 2nd order) with a cut-off frequency of $250 \mathrm{kHz}$. The effects of this filtering on the correlation of measured and LLS inferred peak current is assumed to be insignificant as the sensor bandwidth with an upper frequency of $350 \mathrm{kHz}$ is in the same range. More details about the Gaisberg measurement system can be found in Diendorfer et al. (2009b).

\subsection{Video and field recording system (VFRS)}

To collect video and E-field data of individual lightning discharges, we are employing a mobile video and field recording system (VFRS) consisting of a flat plate antenna, an integrator, a fiber optic link and a camera. For the E-field measurements a 12 bit digitizer with $5 \mathrm{MS} \mathrm{s}^{-1}$ sample rate and an integrator with a decay time constant of $0.46 \mathrm{~ms}$ was used. The complete system has an upper frequency cutoff of 1.3 MHz. The camera used had a frame rate of $200 \mathrm{fps}$ and an angle-of-view of about $50^{\circ}$. The complete recording system is described in detail in Schulz et al. (2005), Schulz and Saba (2009) and Schulz and Diendorfer (2006).

\section{Data}

The lightning data used in this analysis were collected in three different regions covered by the EUCLID LLS (see Fig. 1).

- Region 1 (Fig. 3a) - During summer periods from 2009 to 2012, measurements with the VFRS were carried out at various locations in Austria. In addition, direct lightning current measurements have been performed at the instrumented GBT, close to the city of Salzburg, since 1998.

- Region 2 (Fig. 3b) - In August 2011 ground truth data were collected with the VFRS in Belgium.

- Region 3 (Fig. 3c) - In 2012, during the HyMeX project (Ducrocy et al., 2013; Defer et al., 2015) ground truth data were collected with the VFRS in southern France and in 2013 a separate measurement campaign was organized in the north of France.

The measurement locations for those regions are given in Fig. 3. In Fig. 3a the location of the GBT in Austria is especially indicated. At the GBT a total of 513 flashes (498 negative and 15 bipolar) were recorded from 2005 to 2014, the
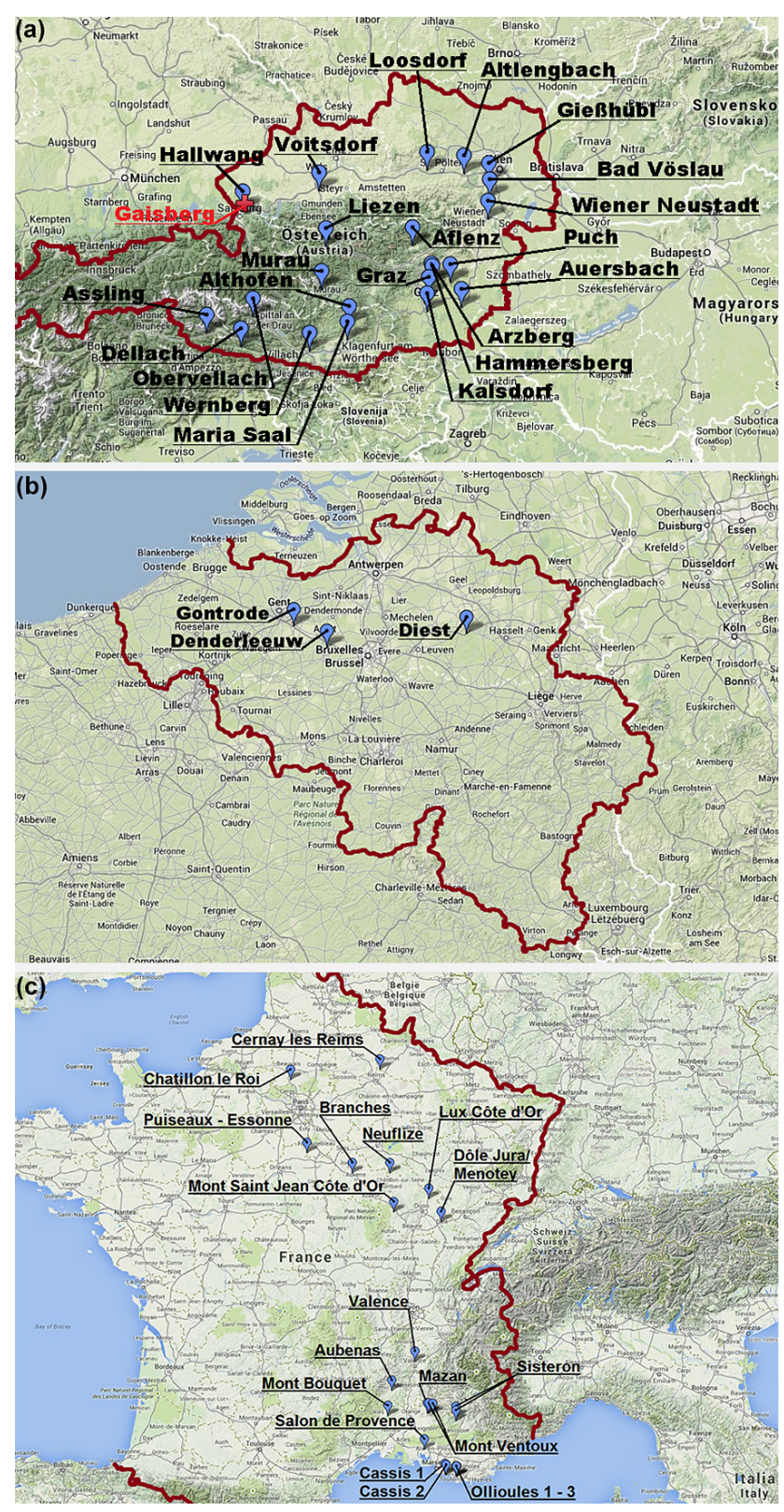

Figure 3. Measurement locations for (a) Austria, (b) Belgium and (c) France.

vast majority of them being upward-initiated discharges. A total of 161 out of the 513 flashes contain 675 return strokes which are used as ground truth reference in this paper. The remaining 352 flashes to the tower exhibit either an initial continuous current (ICC) only or an ICC with superimposed pulses (ICC pulses). Those types of flashes occur solely in upward-initiated lightning and are not representative of natural downward lightning.

With the VFRS we recorded 587 negative flashes in the three distinct regions during 38 days and 156 positive flashes during 21 days (see Table 1). All these recordings were car- 
Table 1. Total number of flashes recorded with the VFRS.

\begin{tabular}{lrr}
\hline & Neg. flashes & Pos. flashes \\
\hline Austria (2008-2012) & 271 & 109 \\
Belgium (2011) & 57 & - \\
France (2012-2013) & 259 & 47 \\
\hline Total & 587 & 156 \\
\hline
\end{tabular}

ried out at 47 different locations shown in Fig. 3. Unfortunately, no positive flashes were recorded in Belgium. Also no positive flashes were recorded in France in 2013.

\section{Results}

\subsection{Location accuracy}

For the analysis of the LLS, LA based on data from the GBT measurements (Region 1) only data from flashes with negative return strokes (including bipolar flashes) were used. For the period 2005-2014 the LLS located 469 out of the 675 return strokes with a median and mean LA of 201 and $343 \mathrm{~m}$ ( $95 \%$ value $1258 \mathrm{~m}$ ), respectively.

Figure 4 plots the moving median of the location error over the last 100 return strokes directly measured at the GBT. The time axis starts at 21 January 2005 because on that day the first strike to the GBT during the period of investigation was recorded. The graph starts on the 20 June 2007 because in the period from 1 January 2005 to 20 June 2007, the 100 strokes occurred, which are needed to start the moving median calculation. The last recorded stroke during the period of interest occurred on 21 October 2014. The improvements in LA due to all the changes in the network described in Sect. 2 are clearly visible in Fig. 4. The moving median location error decreased from $317 \mathrm{~m}$ in 2007 to $89 \mathrm{~m}$ at the end of 2014 . In Fig. 4 also the three major changes in the network, the introduction of the new location algorithm (A), the introduction of the sensor-based onset time calculation (B) and the application of propagation correction (C) are indicated. After each change, a notable increase of LA can be seen.

In order to determine the LA of the LLS with the VFRS data we have to search for strokes that occurred in the same return stroke channel. Due to the reason that almost no positive flashes with multiple strokes in the same channel exist, the LA is determined with negative flashes only. The method to estimate the LLS LA, based on multi-stroke flashes, is described in Schulz et al. (2012) and Biagi et al. (2007). As mentioned in Schulz et al. (2012) this method does not show any systematical location error. Table 2 shows the resulting LA for Austria, Belgium and France.

The LA obtained from all data in Table 2 is better for France compared to Austria because the 2009-2010 measurements in Austria were performed before the implementation of sensor-based onset time calculation, and for mea-

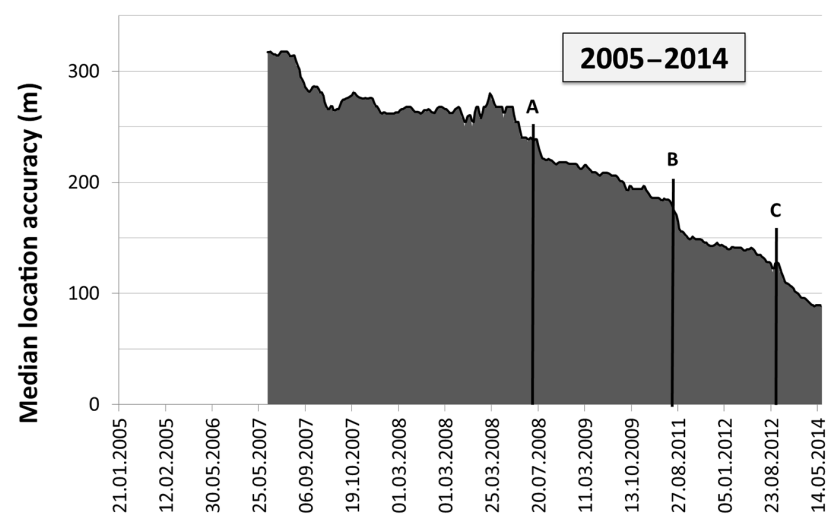

Figure 4. Median location error over time calculated as moving median over the last 100 return strokes measured at the GBT. The vertical lines show the time when the new location algorithm was introduced (A), the introduction of the sensor-based onset time calculation (B) and the application of the propagation correction (C).

surements in 2012 the LLS locations were calculated without propagation corrections.

Figure 5 shows the LLS provided median length of the semi major axis of the confidence ellipse on a $50 \mathrm{~km} \times 50 \mathrm{~km}$ grid for the period 2005-2014 (Fig. 5a) and for the year 2014 only (Fig. 5b). The semi major axis of the confidence ellipse is a measure closely related to the actual location accuracy (Diendorfer et al., 2014). The calculation of the error ellipse is based on the assumption that the time error and angle errors are following a Gaussian distribution. The parameters used for the calculation, namely the standard deviations of the time, and angle error, are determined regularly for each individual sensor. In this figure the contour line for $0.5 \mathrm{~km}$ semi major axis (red line) and the region for the data analyses (black polygon) in the paper Poelman et al. (2016) are displayed. The color coding in Fig. 5 is not discrete but linearly interpolated from blue $(0.1 \mathrm{~km})$ till red $(2.0 \mathrm{~km}$ or greater). Figure 5a shows the median LA over the 10 year period and should give the reader a possibility to assess the LA of the data used in the paper Poelman et al. (2016). Of course the actual performance of the network regarding LA is much better in 2014 and this can be seen in Fig. 5b. A significant improvement can be seen for the 2014 median semi major axis except for a small region in the east of the network (east Slovakia and south-east Poland). This degrade of the network is related to temporary outage of one sensor in Poland and one in Hungary in 2014. In the three regions of the video and E-field measurements, the overall median semi major axis is $0.1 \mathrm{~km}$ and fits well to the latest measured location accuracies at the GBT (see Fig. 4) and in France (see Table 2). Due to the reason that the discretization of the error ellipse given by the location algorithm was $100 \mathrm{~m}$ up to the end of 2014, a median value of $0.1 \mathrm{~km}$ is the lowest possible value we can obtain. Since beginning of 2015 the semi major axis is given by the central analyzer in $10 \mathrm{~m}$ steps. It can be 
Table 2. LA in Austria (Region 1), Belgium (Region 2) and in France (Region 3) obtained from VFRS verified strokes which followed the same channel as a previous stroke in the flash.

\begin{tabular}{lrrrrrrr}
\hline & \multicolumn{2}{c}{ Austria } & \multicolumn{3}{c}{ Belgium } & France \\
\cline { 2 - 8 } & $2009-2010$ & 2012 & All & 2011 & 2012 & 2013 & All \\
\hline$N$ & 119 & 108 & 227 & 25 & 14 & 143 & 157 \\
Median LA (m) & 326 & 157 & 259 & 600 & 256 & 90 & 90 \\
95\% LA (m) & 1629 & 1562 & 1660 & 3315 & 732 & 1665 & 1665 \\
Mean LA (m) & 563 & 430 & 500 & 1207 & 330 & 375 & 372 \\
\hline
\end{tabular}
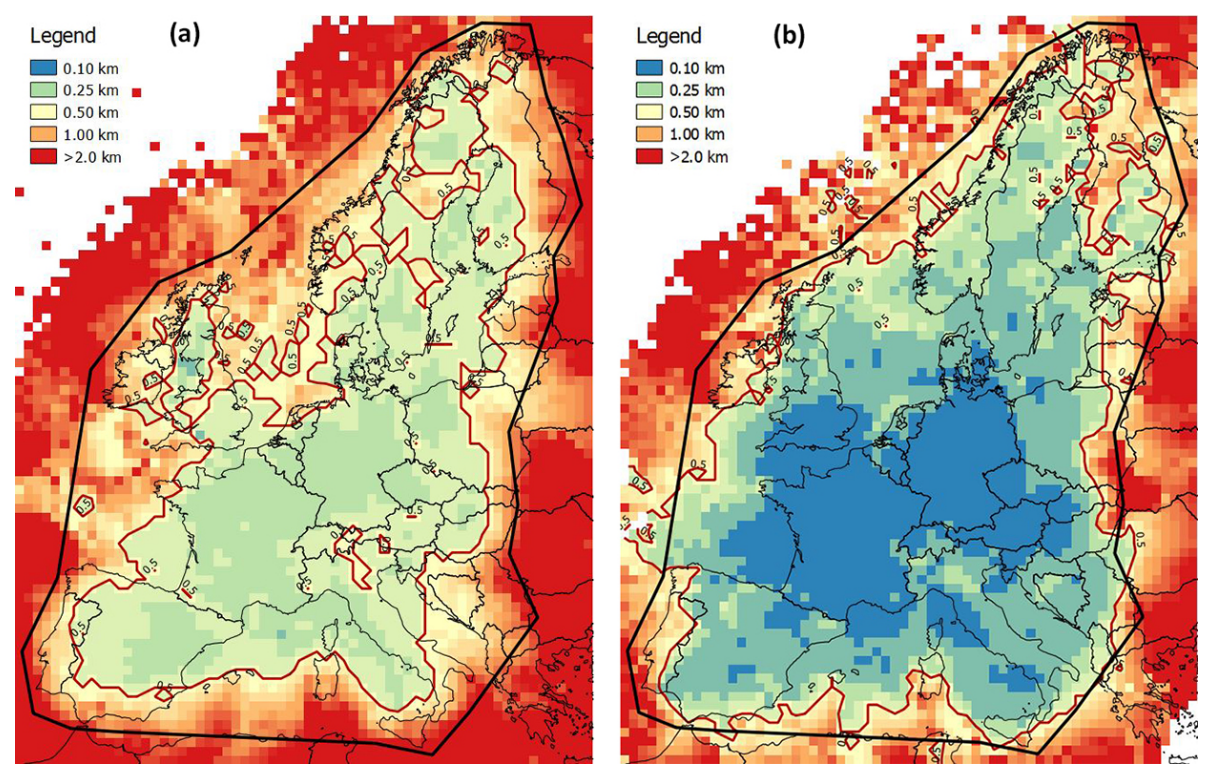

Figure 5. Median semi major axis for the whole EUCLID network for (a) period 2005-2014 and (b) for 2014 only. The black polygon shows the region for the data analysis in Poelman et al. (2016). The red line represents the $0.5 \mathrm{~km}$ contour line of median semi major axis.

seen in Fig. 5b that the estimated location accuracy is better than $500 \mathrm{~m}$ within the majority of the network covered area in 2014.

\subsection{Detection efficiency}

In general it can be shown that the flash/stroke DE increases with increasing peak current (see also Fig. 6a and b). Typically the stroke DE is always lower than the corresponding flash DE because in order to detect a flash it is sufficient to detect one out of several strokes in a multi-stroke flash. The main focus of this paper is on the performance validation of an LLS based on ground truth data. We do not present any spatial flash/stroke DE maps because for this task we would have to use a so called DE model. Model-based DE is still idealized as it does not consider, e.g., any temporary sensor outages due to communication problems. Nevertheless the stroke/flash DE of any network has some spatial variability. The analyses in the companion paper Poelman et al. (2016) are based on flashes because flash DE is less sensitive to network performance and especially larger sensor baselines than stroke DE. Using a reasonable multiplicity distribution it was shown by Schulz et al. (2014a) that in a region of high flash DE a change of stroke DE of $\sim 30 \%$ results in a change of flash DE by only $\sim 10 \%$.

We do not take intra-cloud/cloud-to-ground (IC/CG) classification into account for the Gaisberg data validation because it is documented that the measured field widths related to tower strikes are shorter than for strokes to ground (Diendorfer et al., 2010). This may result in additional misclassification compared to natural lightning and in an underestimation of DE. However we take IC/CG classification into account for video and E-field studies because in this case the data should not be biased by any tower effect.

\subsubsection{DE determined from GBT measurements}

EUCLID flash DE based on the GBT measurements is shown to be greater than $96 \%$ if one of the return strokes in a flash had a peak current greater than $2 \mathrm{kA}$ (Fig. 6a). Flash peak current in Fig. 6a is the peak current of the largest stroke in the flash. All flashes containing at least one stroke with a 

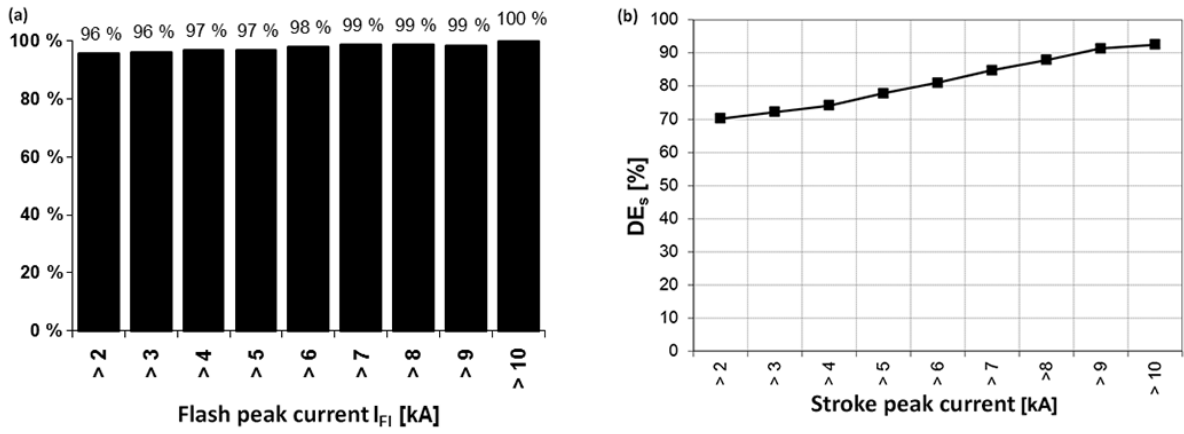

Figure 6. (a) Flash DE and (b) stroke DE determined for negative return strokes at the GBT (2005-2014).

peak current greater than $10 \mathrm{kA}$ were detected $(\mathrm{DE}=100 \%)$. For strokes to the GBT with peak currents greater than $2 \mathrm{kA}$, the stroke DE is $70 \%$ (Fig. 6b).

One has to keep in mind that the analysis of the GBT measurements is made for negative subsequent strokes in upward-initiated flashes only (no first stroke data are available from tower measurements), and therefore the stroke DE mentioned above is a DE for subsequent strokes. A higher average multiplicity in tower-initiated lightning than in natural downward lightning would result in a bias of the DE to higher values, because more strokes in a flash increase the probability of detection, as a flash is detected if at least one of all the strokes is detected. From the current records at the GBT we have determined an average multiplicity of 4.3 return strokes per flash for the period 2005-2014. Figure 7 shows the histogram of the number of return strokes for negative flashes at the GBT. This value is similar to the average multiplicity of three to five strokes per flash observed in natural lightning (CIGRE Report 549, 2013), and therefore we do not expect any bias of the flash DE related to multiplicity. Nevertheless, taking into account that first strokes in natural downward lightning normally have greater peak currents than subsequent strokes, the determined overall flash DE of $96 \%$ (in Fig. 6a) should be interpreted as a lower limit for the DE of EUCLID for natural downward lightning in the same area.

\subsubsection{DE determined from VFRS records}

Due to the reason that the DE did not vary considerably in Austria from 2009 to 2012 and in France in 2012 and in 2013, we present only the average DEs for all the years where data were recorded with the VFRS. The criteria used in Table 3 to determine whether a stroke was detected by the LLS or not are quite strict because not only the stroke location has to be provided with certain quality criteria $\left(\chi^{2}<10\right.$ and major axis of the confidence ellipse smaller than $5 \mathrm{~km}$ ) but also the stroke classification either as cloud-to-ground (CG) or as intra-cloud (IC) has to be correct.

As we have discussed before, the DE depends on peak current, and therefore we present in Table 3 also the median peak

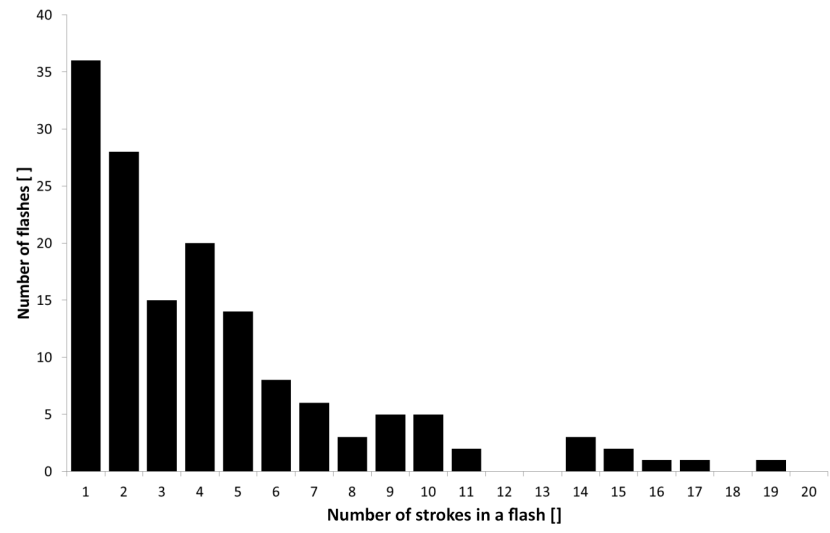

Figure 7. Histogram of number of return strokes in negative flashes to the GBT (2005-2014), sample size $N=150$.

current for negative and positive strokes analyzed in the three regions. The median values are based on LLS-estimated peak currents.

\subsection{Peak current estimates}

The EUCLID peak current estimates are compared with the direct current measurements of strokes to the GBT only because no information regarding peak current is available from the VFRS data records. In Fig. 8 we have plotted the EUCLID-estimated peak current $I_{\text {EUCLID }}$ vs. the directly measured peak current $I_{\mathrm{GB}}$ at the GBT. Ideally all data points should line up on the diagonal (solid black line). Based on the transmission line model (TLM) and the conversion of peak field to peak current used in the EUCLID network, this line corresponds to a return stroke speed of $v_{\text {LLS }}=1.2 \times 10^{8} \mathrm{~m} \mathrm{~s}^{-1}$. Due to different return stroke speeds and propagation paths from the tower to the LLS sensors, the resulting EUCLID peak current estimates scatter around this line. Nevertheless, the overall accuracy seems to be reasonable. It is commonly agreed that most of the observed scatter around a return stroke speed used for the estimation of stroke peak currents (black line in Fig. 8 corresponding to $v=1.2 \times 10^{8} \mathrm{~m} \mathrm{~s}^{-1}$ ) is caused by the stroke by stroke vari- 
Table 3. Flash and stroke DEs determined from VFRS data. The number of flashes/strokes recorded during each of the campaigns is given in the parenthesis. Median peak current is given for strokes used in this analysis.

\begin{tabular}{|c|c|c|c|c|c|c|}
\hline & \multicolumn{2}{|c|}{ Flash DE } & \multicolumn{2}{|c|}{ Stroke DE } & \multicolumn{2}{|c|}{$\begin{array}{c}\text { Median stroke peak } \\
\text { current }\end{array}$} \\
\hline & Positive & Negative & Positive & Negative & Positive & Negative \\
\hline $\begin{array}{l}\text { Austria } \\
\text { (Region 1) }\end{array}$ & $\begin{array}{l}97 \% \\
(109)\end{array}$ & $\begin{array}{l}98 \% \\
(271)\end{array}$ & $\begin{array}{l}92 \% \\
(119)\end{array}$ & $\begin{array}{l}84 \% \\
(928)\end{array}$ & $34 \mathrm{kA}$ & $-12 \mathrm{kA}$ \\
\hline $\begin{array}{l}\text { Belgium } \\
\text { (Region 2) }\end{array}$ & - & $\begin{array}{c}100 \% \\
(57)\end{array}$ & - & $\begin{array}{l}84 \% \\
(210)\end{array}$ & - & $-18 \mathrm{kA}$ \\
\hline $\begin{array}{l}\text { France } \\
\text { (Region 3) }\end{array}$ & $\begin{array}{l}87 \% \\
(47)\end{array}$ & $\begin{array}{l}93 \% \\
(259)\end{array}$ & $\begin{array}{l}84 \% \\
(56)\end{array}$ & $\begin{array}{l}89 \% \\
(833)\end{array}$ & $46 \mathrm{kA}$ & $-16 \mathrm{kA}$ \\
\hline
\end{tabular}

ation of the return stroke speed (Rakov, 2007). In Fig. 8 the blue, green and red lines represent the peak current what EUCLID would report when we assume different return stroke speeds $v_{\text {TLM }}$ for the TLM based peak field calculations.

It is interesting to see that basically all strokes are below the green line for a return stroke speed of $1.5 \times v_{\mathrm{LLS}}$ equal to about $2 / 3$ of speed of light and above the red line representing a return stroke speed of $0.5 \times v_{\text {LLS }}$.

Figure $9 \mathrm{a}$ shows the histogram of the signed EUCLID peak current estimation error as a percentage of the measured peak current at the GBT for 464 return strokes. The arithmetic mean (AM) and the median are 3 and $4 \%$, respectively. When we calculate the absolute values of the EUCLID peak current estimation as percentage, we determine an AM and a median value of $|\Delta I \%|$ of 19 and $18 \%$, respectively (Fig. 9b).

\section{Discussion}

LA of the EUCLID network was determined from GBT measurements for negative subsequent strokes only. Furthermore we cannot obtain any information regarding the LA of positive flashes from VFRS measurements because positive flashes with subsequent strokes in the same channel are rare. Nevertheless, we do not see any reason why the LA for negative first strokes and positive flashes should be different from the validated LA of negative subsequent strokes.

In case of a tower strike the injected current pulses propagating along the tower to ground contribute to the total electromagnetic field radiated by the lightning strokes. Compared to natural lightning strikes to ground, when the lightning channel is often tortuous and branched, the tower is completely straight, and therefore the resulting electromagnetic fields radiated from the tower are probably more suitable to be detected by LLS sensors. As a result, the estimated LA of an LLS based on lightning strikes to towers is expected to be somewhat better than that for natural lightning. On the other hand, the LLS location error determined from video data of strokes in the same channel is an upper limit because

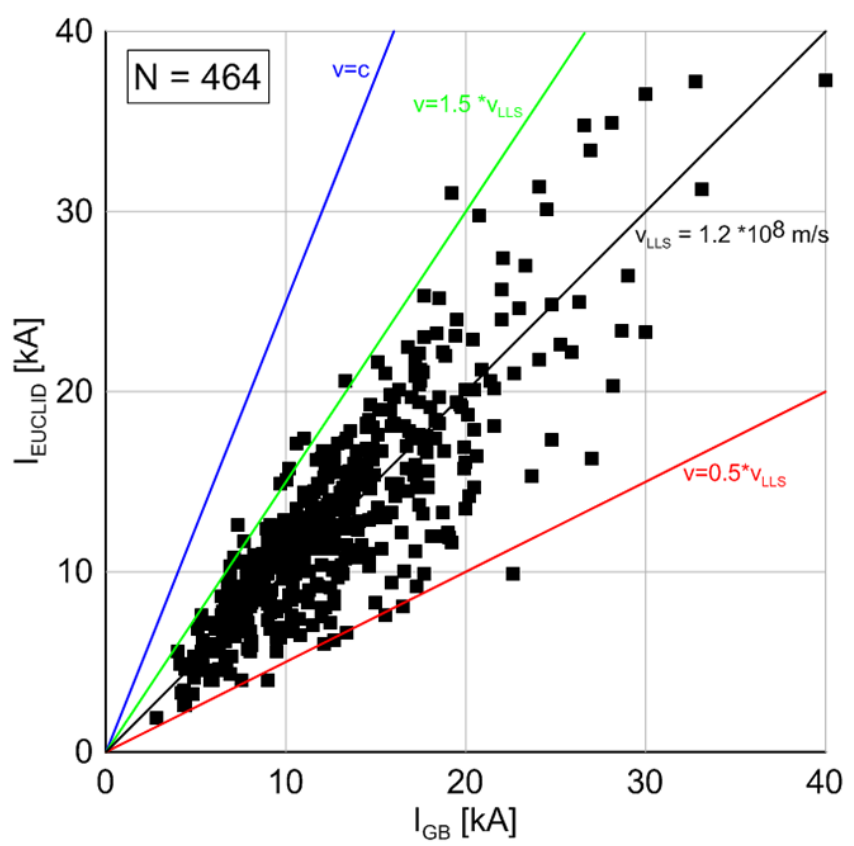

Figure 8. EUCLID peak current estimates plotted vs. directly measured stroke peak currents at the GBT during the time period 20052014. Blue, green, black and yellow lines represent the EUCLID peak currents for different return stroke speed and assuming TLM.

the return stroke channel is not always seen all the way down to the ground strike point of each return stroke (Biagi et al., 2007). Keeping in mind those specific limitations of tower measurements and VFRS recordings, the agreement between LA determined from GBT data and VFRS data in Austria is almost perfect.

Further, we observed a continuous improvement of the LA of the EUCLID network in recent years due to the implementation of several technology improvements (soft- and hardware) summarized in Sect. 2. All these improvements result in an actual median LA of $89 \mathrm{~m}$ for the last 100 strokes recorded at the GBT. 

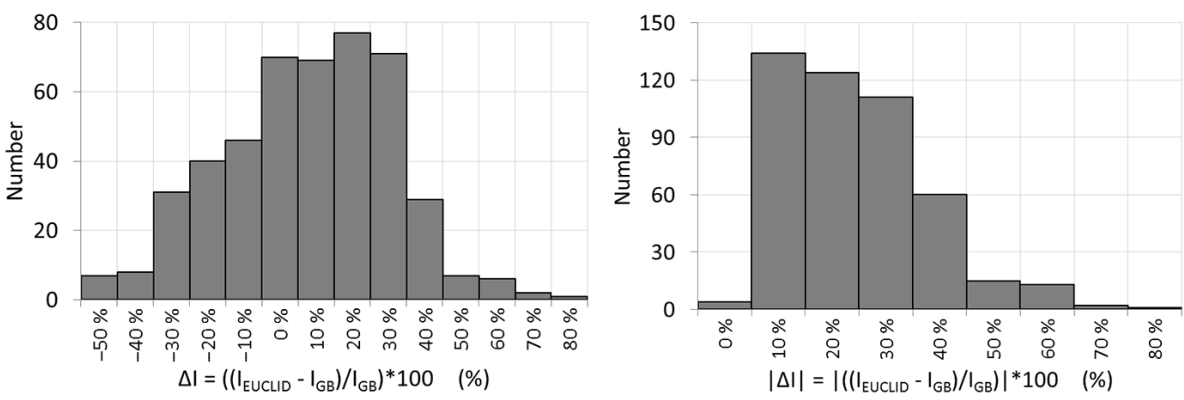

Figure 9. Histograms of (a) signed and (b) absolute EUCLID peak current estimation errors, given as a percentage of the directly measured GBT current $\left(\Delta I \%=\left(\left(I_{\mathrm{EUCLID}}-I_{\mathrm{GB}}\right) / I_{\mathrm{GB}}\right) \times 100\right.$ for 464 return strokes in 2005-2014.

The estimated LA in Belgium was relatively poor in 2011 because during this time there were still several sensors of outdated technology operated around Belgium which had some negative effects on the LA. Since that time, these old sensors installed around Belgium have been upgraded to the newest sensor technology.

The spatial LA estimation by use of the semi major axis of the $50 \%$ confidence ellipses is an appropriate tool to estimate the LA for larger areas. This LA estimation based on real LLS data depends only on the configured standard deviations of the time and angle measurements of each sensor. If those parameters are derived and configured correctly the resulting median LA for certain regions is a real measure of the LA in this region. This was also confirmed with data from the GBT measurements in Diendorfer et al. (2014). The analysis in this paper also shows that the LA determined from ground truth data is in the same range as the LA given by the major axis of the $50 \%$ confidence ellipses for the same region. This gives us the confidence to claim that the LA determined from the distribution of the $50 \%$ confidence ellipses (see Fig. 5b) is representative for the real LA and hence the LA for the EUCLID network is better than $500 \mathrm{~m}$ in the majority of the network.

The DE of 96 and $70 \%$ for negative flashes and strokes, respectively, determined from data to the GBT is in good agreement with the DE determined from VFRS data in Austria (98 and $84 \%$ for flashes and strokes, respectively), considering that the DE from GBT data is based on subsequent strokes only, and first strokes normally exhibit peak currents greater than subsequent strokes. Negative flashes at the GBT exhibit a mean multiplicity of 4.3 strokes per flash which is in the range of multiplicities reported for natural negative downward flashes of 3 to 5 (CIGRE Report 549, 2013). This is important because the multiplicity has a strong influence on the flash DE.

The lower DE for negative flashes in France compared to Austria is a result of a temporary outage of a nearby sensor during the September 2012 measurements campaign. During this time period, nine single-stroke flashes were missed. The low DE for positive flashes is caused by the very strict criteria applied for the analysis, when we rate misclassified strokes as not being detected by the LLS. Eight positive CG strokes were actually located by EUCLID but misclassified as IC (five single-stroke flashes). In fact only one positive flash was not detected at all.

LLS tend to overestimate the peak current of strokes to socalled electrically tall towers (Pavanello et al., 2009). A tower is called electrically tall when the rise time of the lightning current is smaller than the current wave propagation time along the tower, and therefore, the current injected into the tower top reaches its peak before the arrival of any ground reflections. Correction factors have been derived based on model calculations taking into account multiple reflections of the lightning current pulse at ground level and at the top of the tower (Baba and Rakov, 2007; Bermúdez et al., 2005). Based on triggered lightning data for the US, NLDN peak current errors with an AM and median of -5.6 and $-5 \%$, respectively, are reported (Mallick et al., 2014). Contrary to the NLDN, peak current errors in this paper are positive (AM and the median 3 and $4 \%$ respectively) which means that the EUCLID LLS overestimates the peak current compared to the NLDN. This slight overestimation of lightning to the GBT compared to the triggered lightning current measurements at Camp Blanding could possibly be related to some tower enhancement described above but this enhancement is still much smaller than observed at electrically tall towers, e.g., the $553 \mathrm{~m}$ tall $\mathrm{CN}$ Tower.

The results presented in this paper are assumed to be representative for the performance of the EUCLID network in other regions with similar sensor baseline and sensor technology.

Acknowledgements. The authors are grateful to the support from all the EUCLID members. The authors further thank Christian Vergeiner who recorded most of the video and E-field data in Austria and Hannes Pichler who is the master behind the Gaisberg measurements. We also thank the anonymous reviewers for their very helpful comments.

Edited by: A. Mugnai

Reviewed by: K. Cummins and one anonymous referee 


\section{References}

Baba, Y. and Rakov, V. A.: Lightning strikes to tall objects: Currents inferred from far electromagnetic fields versus directly measured currents, Geophys. Res. Lett., 34, L19810, doi:10.1029/2007GL030870, 2007.

Berger, G. and Pedeboy, S.: Comparison Between Real CG Flashes and CG Flashes Detected by a Lightning Detection Network, in: vol. 2, International Conference on Lightning and Static Electricity (ICOLSE), Blackpool, UK, 1-12, 2003.

Bermúdez, J.-L., Rachidi, F., Rubinstein, M., Janischewskyj, W., Shostak, V. O., Pavanello, D., Chang, J.-S., Hussein, A. M., Nucci, C. A., and Paolone, M.: Far-field-current relationship based on the TL model for lightning return strokes to elevated strike objects, IEEE Trans. Electromagn. Compat., 47, 146-159, doi:10.1109/TEMC.2004.842102, 2005.

Biagi, C. J., Cummins, K. L., Kehoe, K. E., and Krider, E. P.: National Lightning Detection Network (NLDN) performance in southern Arizona, Texas, and Oklahoma in 2003-2004, J. Geophys. Res.-Atmos., 112, D05208, doi:10.1029/2006JD007341, 2007.

CIGRE Report 549: Lightning Parameters for Engineering Applications, CIGRE, Paris, 2013.

Defer, E., Pinty, J.-P., Coquillat, S., Martin, J.-M., Prieur, S., Soula, S., Richard, E., Rison, W., Krehbiel, P., Thomas, R., Rodeheffer, D., Vergeiner, C., Malaterre, F., Pedeboy, S., Schulz, W., Farges, T., Gallin, L.-J., Ortéga, P., Ribaud, J.-F., Anderson, G., Betz, H.-D., Meneux, B., Kotroni, V., Lagouvardos, K., Roos, S., Ducrocq, V., Roussot, O., Labatut, L., and Molinié, G.: An overview of the lightning and atmospheric electricity observations collected in southern France during the HYdrological cycle in Mediterranean EXperiment (HyMeX), Special Observation Period 1, Atmos. Meas. Tech., 8, 649-669, doi:10.5194/amt8-649-2015, 2015.

Diendorfer, G.: EUCLID - Technical Structure and Performance of the European wide Lightning Location System, in: International Conference on Grounding and Earthing and Brazilian Workshop on Atmospheric Electricity (GROUND/WAE), Rio de Janeiro, Brazil, 2002.

Diendorfer, G., Hadrian, W., Hofbauer, F., Mair, M., and Schulz, W.: Evaluation of Lightning Location Data Employing Measurements of Direct Strikes to a Radio Tower, Cigre Sess., Paris, 33206, 2002.

Diendorfer, G., Bernardi, M., Cummins, K. L., Del la Rosa, F., Hermoso, B., Hussein, A. M., Kawamura, T., Rachidi, F., Rakov, V. A., Schulz, W., Torres, H., and De Rosa, F.: Cloud-to-Ground Lightning Parameters derived from Lightning Location Systems, in: The Effects of System Performance, Electra, CIGRE, Paris, 2009a.

Diendorfer, G., Pichler, H., and Mair, M.: Some Parameters of Negative Upward-Initiated Lightning to the Gaisberg Tower (2000-2007), IEEE Trans. Electromagn. Compat., 51, 443-452, doi:10.1109/TEMC.2009.2021616, 2009b.

Diendorfer, G., Schulz, W., and Pichler, H.: Zero-Crossing Time and Pulse width of Radiated Fields from Lightning to Elevated Objects, in: International Conference on Grounding and Earthing and International Conference on Lightning Physics and Effects (GROUND/LPE), Salvador, Brazil, 241-243, 2010.

Diendorfer, G., Pichler, H., and Schulz, W.: EUCLID Located Strokes to the Gaisberg Tower - Accuracy of Location and its assigned Confidence Ellipse, in: International Lightning Detection Conference and International Lightning Meteorology Conference (ILDC/ILMC), Tucson, 2014.

Djurica, V. and Kosmač, J.: LLS Accuracy Improvements by Measurements Collected by RLDN, in: 19th International Lightning Detection Conference (ILDC) 1st International Lightning Meteorology Conference (ILMC), Tucson, Arizona, USA, 2006.

Djurica, V., Milev, G., and Kosmač, J.: Lightning Location Networks Performance Validation with RLDN, in: International Symposium on High Voltage Engineering (ISH), Cape Town, South Africa., 1-4, 2009.

Drüe, C., Hauf, T., Finke, U., Keyn, S., and Kreyer, O.: Comparison of a SAFIR lightning detection network in northern Germany to the operational BLIDS network, J. Geophys. Res.-Atmos., 112, D18114, doi:10.1029/2006JD007680, 2007.

Ducrocy, V., Braud, I., Davolio, S., Ferretti, R., Flamant, C., Jansa, A., Kalthoff, N., Richard, E., Taupier-Letage, I., Ayral, P.-A., Belamari, S., Berne, A., Borga, M., Boudevillain, B., Bock, O., Boichard, J.-L., Bouin, M.-N., Bousquet, O., Bouvier, C., Chiggiato, J., Cimini, D., Corsmeier, U., Coppola, L., Cocquerez, P., Defer, E., Delanoë, J., Girolamo, P. Di, Doerenbecher, A., Drobinski, P., Dufournet, Y., Fourrié, N., Gourley, J. J., Labatut, L., Lambert, D., Le Coz, J., Marzano, F. S., Molinié, G., Montani, A., Nord, G., Nuret, M., Ramage, K., Rison, B., Roussot, O., Said, F., Schwarzenboeck, A., Testor, P., Van Baelen, J., Vincendon, B., Aran, M., and Tamayo, J.: HyMeX-SOP1, the field campaign dedicated ot heavy precipitation and flash flooding in the northwestern Mediterranean, Am. Meteorol. Soc., 95, 10831100, doi:10.1175/BAMS-D-12-00244.1, 2013.

Honma, N., Suzuki, F., Miyake, Y., Ishii, M., and Hidayat, S.: Propagation effect on field waveforms in relation to time-of-arrival technique in lightning location, J. Geophys. Res.-Atmos., 103, 14141-14145, doi:10.1029/97JD02625, 1998.

Honma, N., Cummins, K. L., Murphy, M. J., Pifer, A. E., Rogers, T., and Tatsumi, M.: Improved Lightning Locations in the Tohoku Region of Japan using Propagation and Waveform Onset Corrections, in: vol. 133, International Symposium on Winter Lightning (ISWL), Research and Development Center, Tohoku Electric Power Company, Inc., Nakayama, Aoba-ku, Sendai, Japan, 1-6, available at: http://www.scopus. com/inward/record.url?eid=2-s2.0-84874174004\&partnerID= 40\&md5=303a9d646768ddb456c75d40f35c802b (last access: 2 September 2015), 2011.

Mallick, S., Rakov, V. A., Hill, J. D., Ngin, T., Gamerota, W. R., Pilkey, J. T., Biagi, C. J., Jordan, D. M., Uman, M. A., Cramer, J. A., and Nag, A.: Performance characteristics of the NLDN for return strokes and pulses superimposed on steady currents, based on rocket-triggered lightning data acquired in Florida in 2004-2012, J. Geophys. Res.-Atmos., 119, 38253856, doi:10.1002/2013JD021401, 2014.

Nag, A., Murphy, M. J., Schulz, W., and Cummins, K. L.: Lightning Locating Systems: Insights on Characteristics and Validation Techniques, Earth Space Sci., 2, 65-93, doi:10.1002/2014EA000051, 2015.

Pavanello, D., Rachidi, F., Janischewskyj, W., Rubinstein, M., Shostak, V. O., Nucci, C. A., Cummins, K. L., Hussein, A. M., and Chang, J.-S.: On the Current Peak Estimates Provided by Lightning Detection Networks for Lightning Return Strokes to 
Tall Towers, IEEE Trans. Electromagn. Compat., 51, 453-458, doi:10.1109/TEMC.2009.2025913, 2009.

Pédeboy, S., Defer, E., and Schulz, W.: Performance of the EUCLID network in cloud lightning detection in the South-East France, in: 8th HyMeX Workshop, Valletta, Malta, 2014.

Poelman, D. R., Honoré, F., Anderson, G., and Pedeboy, S.: Comparing a Regional, Subcontinental, and Long-Range Lightning Location System over the Benelux and France, J. Atmos. Ocean. Tech., 30, 2394-2405, doi:10.1175/JTECH-D-1200263.1, 2013a.

Poelman, D. R., Schulz, W., and Vergeiner, C.: Performance Characteristics of Distinct Lightning Detection Networks Covering Belgium, J. Atmos. Ocean. Tech., 30, 942-951, doi:10.1175/JTECH-D-12-00162.1, 2013b.

Poelman, D. R., Schulz, W., Diendorfer, G., and M., Bernardi: The European lightning location system EUCLID - Part 2: Observations, Nat. Hazards Earth Syst. Sci., 16, 607-616, doi:10.5194/nhess-16-607-2016, 2016.

Rakov, V. A.: Lightning Return Stroke Speed, J. Light. Res., 1, 8089, 2007.

Schulz, W. and Diendorfer, G.: EUCLID Network Performance and Data Analysis, in: International Lightning Detection Conference (ILDC), Tucson, Arziona, USA, 2-7, 2002.

Schulz, W. and Diendorfer, G.: Flash Multiplicity and Interstroke Intervals in Austria, in: International Conference on Lightning Protection (ICLP), Kanazawa, Japan, 402-404, 2006.
Schulz, W. and Saba, M. M. F.: First Results of Correlated Lightning Video Images and Electric Field Measurements in Austria, in: International Symposium on Lightning Protection (X SIPDA), Curitiba, Brazil, 2009.

Schulz, W., Lackenbauer, B., Pichler, H., and Diendorfer, G.: LLS data and correlated continous E-Field measurements, in: International Symposium on Lightning Protection (VIII SIPDA), Sao Paulo, Brazil, 2005.

Schulz, W., Vergeiner, C., Pichler, H., Diendorfer, G., and Cummins, K. L.: Location Accuracy Evalution of the Austrian Lightning Location Systems ALDIS, in: International Lightning Detection Conference and International Lightning Meteorology Conference (ILDC/ILMC), Broomfield, Colorado, USA, 2012.

Schulz, W., Pedeboy, S. and Saba, M. M. F.: LLS Detection Efficiency of Ground Strike Points, in: International Conference on Lightning Protection (ICLP), 381-384, 2014a.

Schulz, W., Pedeboy, S., Vergeiner, C., Defer, E., and Rison, W.: Validation of the EUCLID LLS during HyMeX SOP1, in: International Lightning Detection Conference and International Lightning Meteorology Conference (ILDC/ILMC), Tucson, Arizona, USA., 2-5, 2014b. 